\title{
Publicación de autos sacramentales en el siglo XVII: volúmenes propios, colectivos y misceláneas*
}

\author{
Publishing sacramental plays in $17^{\text {th }}$ century: \\ own hand and collective works, and miscellanies
}

\author{
Davinia Rodríguez Ortega \\ Universidad Pública de Navarra \\ davinia.rodriguez@unavarra.es \\ ORCID iD: https://orcid.org/0000-0003-3179-0423
}

RESUMEN: El presente artículo ofrece una recopilación de todas las ediciones aparecidas en el siglo XVII en España que contienen, total o parcialmente, autos sacramentales de los mejores ingenios de la época. De este modo, se estudian los volúmenes de Calderón de la Barca, Valdivielso o Lope de Vega, además de las misceláneas de Tirso de Molina o Pérez de Montalbán entre otros; además se presta una especial atención a las condiciones y motivos de cada tomo, para intentar configurar el panorama editorial de los autos en ese momento histórico. Tras el análisis puede confirmarse la precaria situación en que se encontraba el mercado libresco de autos, como consecuencia de que no eran textos demandados por el público para su lectura, ni por tanto impresos.

Palabras clave: autos sacramentales, imprenta, Calderón de la Barca, Valdivielso, Lope de Vega.

ABSTRACT: This article offers a compilation of all the editions that contain some sacramental plays of the best Golden Age writers published during the $17^{\text {th }}$ century in Spain. Therefore, there are studies the volumes by Calderón de la Barca, Valdivielso or Lope de Vega, as well as the miscellanies by Tirso de Molina or Pérez de Montalbán, amongst others; there is a special interest to examine the conditions and reason for each volume, in order to configure the editorial panorama of the autos in this historical moment. After the analysis, we are able to confirm the precarious situation of

\footnotetext{
* Este trabajo se ha llevado a cabo gracias a una ayuda posdoctoral de la Universidad Pública de Navarra.

Copyright: (C) 2018 CSIC. Este es un artículo de acceso abierto distribuido bajo los términos de la licencia de uso y distribución Creative Commons Reconocimiento 4.0 Internacional (CC BY 4.0).
} 
the librarian market regarding the publication of sacramental plays; the main reason for that context is the lack of interest to read this plays, so, as a consequence, they were not printed.

Keywords: sacramental plays, press, Calderón de la Barca, Valdivielso, Lope de Vega.

\section{INTRODUCCIÓN}

Resulta llamativo el escaso número de ediciones de autos sacramentales que se imprimieron en España durante el Siglo de Oro, aun cuando se trataba de un género teatral con una presencia esencial en la literatura de este periodo; pero no solo eso, sino que formaba parte de las festividades del Corpus Christi, extendiendo su importancia a la mayoría de habitantes de la católica España (al menos en las grandes ciudades, donde más fastuosas eran las celebraciones).

Durante el siglo XVII únicamente José de Valdivielso (1622) y Pedro Calderón de la Barca (1677) se encargaron del proyecto editorial que llevaría a la imprenta una selección de sus piezas sacramentales. En el caso de Lope de Vega, fue su amigo Ortiz de Villena el responsable de esta tarea, al considerar injusta la situación en la que se hallaban estas obras. Asimismo, existe un grupo de autores constituido por el propio Lope, Pérez de Montalbán y Tirso de Molina, que insertaron un número reducido (entre dos y cuatro) de autos en obras de carácter misceláneo. Finalmente, se publicaron tres volúmenes colectivos $(1655,1664$ y 1675) que pretendían dar cuenta de los textos sacramentales fruto de las más destacadas plumas áureas y no impresos con anterioridad ${ }^{1}$. La razón subyacente tras esta precariedad sería de índole económica: como bien señaló el propio Lope, escribía sus comedias por el beneficio pecuniario que le reportaban, no por amor al oficio; sin duda era un trabajo cansado y laborioso ${ }^{2}$.

En el caso de las comedias, los ingresos que recibía el escritor provendrían de dos vías: la venta del texto al autor de comedias para su puesta en escena y el permiso para imprimir las obras adjudicadas al librero y mercader de turno. Por esta razón, de nuevo volviendo al caso de Lope, se publicaron hasta veinticinco partes de comedias con sus escritos, algunas bajo su supervisión, otras sin su permiso, y las cinco últimas de manera póstuma. Sin embargo, el Fénix únicamente publicó cuatro autos sacramentales dentro de la miscelánea El peregrino de su patria. El caso de Calderón es menos llamativo, pero tampoco iguali-

\footnotetext{
${ }^{1}$ En su tesis doctoral, Gómez Sánchez-Ferrer (2015: 485-513) se dedica a estudiar en profundidad esta situación editorial de los autos sacramentales en el siglo XVII.

${ }^{2}$ Para ampliar y matizar este aspecto puede consultarse la monografía del experto investigador García Reidy (2013), donde desarrolla ampliamente la profesionalización del escritor en el caso de Lope de Vega.
} 
tario: publicó dos partes de comedias en vida, con la ayuda de su hermano José, y dos décadas después imprimió una primera parte de autos, que aunque invitaba a una continuación, permaneció como un acontecimiento aislado ${ }^{3}$.

Y continuando con el razonamiento lógico, si los dramaturgos no se molestaron en poner en limpio sus textos para llevarlos a la imprenta, podemos hallar la razón en la falta de beneficio comercial de tal empresa, que no encontraría el interés del público lector. La venta de comedias, en partes y sueltas, constituía un gran negocio en el Siglo de Oro español, aportando sustanciosos ingresos a impresores y libreros, pero no solo, también a encuadernadores, vendedores de piel y papel, etc., siendo sin duda un elemento esencial en la economía española del momento. Por el contrario, no sucedía lo mismo en el caso de los autos: la impresión y comercio de los ejemplares no constituiría importantes ingresos, lejos de la música y la tramoya del Corpus. Como veremos a continuación, ya excusaban estas faltas Valdivielso y Calderón, siendo conscientes de la gran pérdida que experimentaban este tipo de textos en su paso al papel impreso. Mas la falta de interés no solo se acusa por la carencia de fascinación sensorial que conllevaría la lectura, sino por la aridez de los conceptos que recreaba, llevando incluso a la incomprensión, según Arellano y Duarte (2003: 19): "Es obvio que gran parte del público entendería poco de los razonamientos teológicos, ni podría captar las citas y glosas de los padres de la Iglesia y lugares doctrinales aducidos con gran intensidad por muchos autores, pero eso no era óbice para que el espectáculo sacramental consiguiera la adhesión emocional que perseguía".

En el momento de la lectura faltaban los pasacalles, las tarascas, el desfile de autoridades, la custodia, etc., pero también el sentido de comunidad en la celebración de uno de los días más importantes en el calendario católico según indican Arellano y Duarte (2003: 33): "El espectador-fiel cristiano debe participar y el canal comunicativo debe asegurarse si quiere cumplirse el objetivo", que no era otro que ensalzar la Eucaristía a través de la celebración colectiva. Por tanto, escasas serían las ocasiones en que un habitante de la España aurisecular se dispusiera a leer un auto sacramental, cuyas versiones impresas tendrían como destinatarios más comunes las personas de fe, que no solamente supieran leer, sino que además comprendieran el entramado bíblico y mitológico que atesoraban estos escritos.

En conclusión, por el carácter mismo del auto sacramental como género teatral relacionado de manera intrínseca e indisoluble con la fiesta del Corpus,

${ }^{3}$ Al menos le harán justicia los editores del XVIII, que publicarán su obra completa: Vera Tassis encargado de las comedias y Pando de los textos sacramentales. Este último, junto con el resto de editores dieciochescos de autos calderonianos ha sido estudiado por Ruano de la Haza (1995 y 2015). 
se configura como una muestra de teatro para ser vista, no para ser leída ${ }^{4}$. De ahí deriva la siguiente situación: si no se leen, no se venden y por tanto no se imprimen.

De cualquier modo, al tratarse de un corpus limitado y por ende curioso, vamos a analizar cada una de las publicaciones del siglo XVII que de forma total o parcial contienen autos sacramentales. La estructura seguida en su estudio será siempre la misma: título, autos incluidos, datos de impresión (impresor y librero) y cuestiones generales dignas de mención. También hemos seguido un orden cronológico para así facilitar la construcción del paisaje que presenta la edición de autos en la época de su máximo esplendor.

\section{ESTUDIO}

1. El peregrino en su patria, de Lope de Vega, publicado en Sevilla, por Clemente Hidalgo, 1604.

- Autos: El viaje del alma; Las bodas del alma y el amor divino; La maya; El hijo pródigo ${ }^{5}$.

- Datos de impresión: El fecundo impresor Hidalgo tenía su taller en Sevilla, y según afirma Pedraza6: "Su labor se extiende, a lo que sabemos, desde 1599 a 1615", aunque Delgado Casado (1996: 322-323) nos ofrece otra fecha: "inicia su actividad en 1598, año en que realiza en el Colegio de San Hermenegildo, con Juan René, Comentatiorum in Job de Juan Pineda". Su trabajo se detiene entre 1616 y 1621 , periodo del que no se conservan datos, aunque su imprenta siguió más tarde en activo a través de su viuda, a partir de ese último año.

Lope aprovechó por tanto su estancia en la ciudad hispalense para publicar este volumen misceláneo además de sus conocidas Rimas, con la misma fecha de publicación y datos de imprenta.

En el volumen no se consigna información alguna acerca del librero.

- Sobre la edición: Lope inserta cuatro autos sacramentales en este volumen

\footnotetext{
${ }^{4}$ Así lo afirma Gómez Sánchez-Ferrer (2015: 490): "No cabe duda, en fin, de que el negocio de los autos era puramente escénico". Y más adelante, en nota al pie, añade: "En palabras de García Reidy: "La escritura dramática de autos sacramentales se movió en los parámetros propios de un mercado, fundado en la diferencia entre la demanda existente (las ciudades o compañías que querían disponer de autos de Lope) y la oferta disponible (el limitado número de obras que el Fénix podía escribir cada año), así como en la competencia entre diversos clientes para hacerse con los servicios". De dicho modelo mercantil, como se puede ver, quedaba totalmente excluido cualquier tipo de rentabilización posterior de los textos a la manera en que se consiguió en la industria editorial de la comedia nueva; su manera de obtener beneficio de los textos sacramentales se oponía frontalmente a tal modelo de negocio subsidiario" (2015: 490, nota 4).

5 Según Urzáiz Tortajada (2002: 686), citando a Miguel Gallo: "Un auto con este título iba a ser representado en Burgos, en 1629".

${ }^{6}$ Se recoge en la edición crítica de las Rimas (Pedraza, 1993: 124).
} 
de carácter novelesco, publicado bajo su supervisión en 1604. De hecho, es la única edición en la que el Fénix decide dar cabida a sus piezas religiosas, aunque como veremos a continuación, los sitúa más bien a modo de refuerzo a la estructura de El peregrino, no en el centro de su interés. Como consecuencia, es lógico pensar que el dramaturgo consideraba los autos sacramentales representaciones de una forma de teatro menor.

El peregrino de Lope está dividido en cinco libros: al final de los cuatro primeros se sitúa el auto correspondiente, mientras que el quinto queda exento. Según afirma el propio autor, su intención era prolongar esta obra con una segunda parte, proyecto que nunca llegó a realizarse; a lo largo de este trabajo veremos varios casos en los que se emplaza al lector a una continuación frustrada. Avalle-Arce (1973: 24), el editor moderno de El peregrino, explica la disposición de los textos en la obra: "la inclusión de obras dramáticas cumple, en primer lugar, una clara función estructurante, ya que éstas son el instrumento de la simetría arquitectónica de la novela". La coherencia se expone a nivel externo, pero también en lo relativo al contenido: "El caso es que a través de los autos sacramentales o representaciones morales afines, ciertas doctrinas teológicas, con buenas dosis de catecismo, llegaban eficazmente al público de los corrales o de las plazas. Ahora, en nuestra obra, se trata de que esas mismas doctrinas lleguen al público lector de novelas, envueltas en las páginas de $E l$ peregrino" (1973: 26).

Como consecuencia, indica el editor, la obra completa se configura como un producto propagandístico al servicio del Concilio de Trento y la Contrarreforma, mediante la cual Lope aprovecha la ociosa página novelesca para acercar los presupuestos catequéticos a sus lectores.

2. Doce autos sacramentales, y dos comedias divinas, de José de Valdivielso, en Toledo, por Juan Ruiz, a costa de Martín Vázquez de la Cruz, 1622.

- Autos: El villano en su rincón; El hospital de los locos; Los cautivos libres; El fénix de amor; La amistad en el peligro; Psique, y Cupido, Cristo, y el alma ${ }^{7}$; El hombre encantado; Las ferias del alma ${ }^{8}$; El peregrino ${ }^{9}$; De la serrana de Plasencia ${ }^{10}$; Del hijo prodigo; Árbol de la vida.

Comedias "divinas": El nacimiento de la mejor; Del ángel de la guarda.

\footnotetext{
${ }^{7}$ Urzáiz Tortajada (2012: 644): "Representado en Sevilla, en 1621, por la compañía de Juan Bautista Valenciano".

${ }^{8}$ Acerca de su puesta en escena y tradición manuscrita, Urzáiz Tortajada (2012: 644): "Representado en Sevilla, en 1607, por la compañía de Gaspar de Porras. BNM, Ms. 15.283".

${ }^{9}$ Urzáiz Tortajada (2012: 644): "En 1610, se representó en Burgos un auto titulado El peregrino de Jericó, que Miguel Gallo [...] cree pudo ser éste".

${ }^{10}$ Urzáiz Tortajada (2012: 645): "Representado en Sevilla durante las fiestas del Corpus de 1619, por la compañía de Juan Acacia. BNM, Ms. 11.677”.
} 
- Datos de impresión: Juan Ruiz fue: "Impresor. Natural de Covarrubias. Se asentó como aprendiz de «componedor de letras» con Luis Sánchez, por cuatro años, el 17 de octubre de 1602" (Agulló y Cobo, 1991: 282)11. Dos décadas después ya imprimía en su propio taller.

Sin información del librero Martín Vázquez de la Cruz.

- Sobre la edición: Se publica en 1622 con el consentimiento del autor, que es el que recoge los títulos para ofrecérselos a su buen amigo, el cardenal infante don Fernando, arzobispo de Toledo. Es el primer dramaturgo que en el siglo XVII compila algunas de sus piezas sacramentales para darlas a la imprenta:

El avance que trajo consigo la manera de imprimir estos autos sacramentales, pese a su carácter periférico como libro de teatro, es bien notable. No solo supuso la primera apuesta editorial del siglo por el auto como materia digna de una lectura - sin necesidad de insertarlo en un contexto narrativo- sino que además lo hizo en igualdad de condiciones y en paralelo a varios ejemplos de comedia nueva. Su modelo, desde luego, es el que dará pie más tarde a ediciones bien conocidas, como la que se hizo de las piezas del Fénix en 1644 bajo el título de Fiestas del Santísimo Sacramento repartidas en doce autos sacramentales con sus loas y entremeses (Zaragoza, Pedro Vergés, 1644) (Gómez Sánchez-Ferrer, 2015: 500).

Cuatro décadas más tarde hará lo propio el maestro Calderón, y no es casualidad que estos dos ingenios sean de los más destacados en el cultivo del género.

Es consciente Valdivielso de la pérdida que supone la versión en papel de los autos frente a su escenificación, menoscabo que certifica en el caso de los textos aquí recogidos en la siguiente afirmación: "No pienso que desmerecerán estos autos impresos el buen pasaje que gozaron representados, pues a vista de los mejores concursos de España persuadieron aplausos no vulgares, motivo primero de sacarlos por segunda vez a la plaza del mundo..." (Valdivielso, 1622: "Al lector", s. p.) ${ }^{12}$. El público que potencialmente leería los autos no sería el más amplio, regocijado y entretenido de las comedias, sino uno más restringido: "personas retiradas de divertimentos esparcidos", que buscarían el concepto y no la risa.

De entre toda su producción sacramental, elige doce títulos, a los que acompaña de dos comedias divinas, situación editorial que como veremos se repite en muchas ocasiones. Según el dramaturgo, se trata de los autos más originales "por de pensamientos no trillados y que han afectado imitar ingenios ilustres...", y como indica Duarte (2013), bien cierta es la segunda afirmación. La relación

${ }^{11}$ También se mencionan otros dos impresores con el mismo nombre, a todas luces común: uno en el taller de Francisco Nieto de Salcedo, activo en 1656 y otro en México.

${ }^{12}$ Existe una edición digital del prólogo a cargo de Marcello (s. f.). 
entre Valdivielso en cuestión de materia literaria con otros autores contemporáneos (Lope de Vega y Cervantes) es intensa, aunque más destacable es la influencia que ejerce en Calderón, por ser este el escritor más prolífico y con el que más probabilidades de coincidencia existían:

Son varios los artículos en los que se demuestra la relación de Valdivielso y Calderón, empezando por el de Louise Fothergill-Payne que lleva el significativo título de "José de Valdivielso, censor y precursor de Calderón". Esta relación de los dos escritores ha sido también señalada por muchos críticos como Ricardo Arias (quien estudia la comedia El nacimiento de la mejor comparándola con La hidalga del valle), Ignacio Arellano (estudiando El árbol del mejor fruto de Calderón y El árbol de la vida del maestro toledano), Elena Marcello (al estudiar un poema de Valdivielso, "El sagrario de Toledo", fuente de la comedia calderoniana Origen, fuente y restauración de la Virgen del Sagrario) y Enrique Rull, quien edita el auto de Valdivielso Psiques y Cupido, edición en la que hace numerosísimas referencias a los dos autos calderonianos (el de Toledo y de Madrid) que llevan el mismo título (Duarte, 2013: s. p.) ${ }^{13}$.

Y bien es cierto que el interesado en literatura aurisecular reconocerá ecos bíblicos, míticos o intertextuales en títulos como El villano en su rincón, La serrana de Plasencia o El hijo pródigo.

Agradecerá el lector, por tanto, la "supuesta" insistencia del arzobispo toledano para que su ingenioso amigo publicara parte de su producción sacramental.

3. Para todos, ejemplos morales, humanos y divinos en que se tratan diversas ciencias, materias y facultades: repartidos en los siete días de la semana, de Pérez de Montalbán, en Madrid, en la Imprenta del Reino, a costa de Alonso Pérez [su padre], 1632.

- Autos: Escanderbech ${ }^{14}$; Polifemo.

- Datos de impresión: Acerca de la Imprenta del Reino existen pocos datos: "Por el nombre, se puede suponer que era un taller dependiente de la "Diputación General de Reino" lo que le convierte en una institución paralela a la "Imprenta Real", pero totalmente independiente" (Delgado Casado, 1996: 341). Funcionó entre 1628-1698 sin un taller fijo, sino que las impresiones a su cargo se realizaban en las imprentas propias de los maestros al cargo.

Como bien afirma la portada del volumen, el librero Alonso Pérez fue el padre del escritor Pérez de Montalbán. Prolífico comerciante y librero del rey, ejerció su profesión entre 1591 y 1645, mudándose a Valladolid con la Corte,

13 El artículo profundiza más adelante en la relación entre Valdivielso y Calderón a nivel puramente textual; Duarte analiza algunas obras destacadas de ambos escritores siguiendo el concepto de "microestructura" propuesto por Arellano.

${ }^{14}$ Urzáiz Tortajada (2012: 514): "Escrito hacia 1629, y representado por Roque en Madrid. BNM, Ms. 15.213”. 
para después volver a Madrid. Su negocio estaba situado en la Puerta de Guadalajara, calle de Santiago (Agulló y Cobo, 1991: 234-238)15.

- Sobre la edición: Esta miscelánea publicada en Madrid en $1632^{16}$ contiene obras variadas: noticias, poesías, novelas, comedias y autos sacramentales. Según hemos anotado anteriormente, se contienen dos títulos en representación de este último género literario: Escanderbech y Polifemo. Tal y como puede comprobarse en el ampuloso título, Pérez de Montalbán trata de impregnarlo de una esencia religiosa y moral, en un momento en que la negativa de publicar comedias y novelas por parte del Consejo de Castilla se encuentra vigente. Sin embargo, no es la única ocasión en que el librero Alonso Pérez trata de seguir con su negocio a pesar la prohibición:

Las prensas de los reinos de Castilla lanzan ediciones falsificadas, simulando ser de impresores de otros reinos, o contrahacen las ediciones que en estos reinos se imprimen de obras nuevas. El 16 de mayo de 1627, eran condenados el librero-editor Alonso Pérez, padre de Juan Pérez de Montalbán, y la impresora Francisca de Medina, viuda de Alonso Martín, por su edición contrahecha del Buscón de Quevedo, publicado en 1626, en Zaragoza (Moll, 1992: s. p. $)^{17}$.

Un hecho que también sucede en el caso del Para todos de Pérez de Montalbán, según confirma la fecha de su publicación, 1632. Fray Jerónimo de Vera escribe una carta en la que denuncia esta situación, utilizando de un modo sagaz una recreación humorística de un elemento paratextual de las publicaciones:

En su aprobación paródica al Para Todos, Vera manifiesta su acuerdo con la decisión del Consejo, y denuncia la superchería: "no hallo en el [libro] cosa alguna [...] que no solicite exemplar castigo, assi del Consejo Real que ya no consiente libres vanos". Comenta luego la estructura del libre "dividido en los siete días de la semana, para referir lo que Dios hizo en cada uno dellos, y la fábula del Planeta; y esto porque quatro Comedias y otras tantas Novelas hagan mayor volumen, y así disfrazadas salgan a luz contra el prudentísimo decreto que les prohíbe la estampa" (Cayuela, 1993: 55-56) ${ }^{18}$.

15 Existe una obra monográfica de Cayuela (2005) dedicada a este librero madrileño.

16 Además de las cuestionables circunstancias en las que se imprimió esta edición, el contenido de la obra también generó fuertes polémicas en su tiempo; según recoge Plata (2005), una de las más inmediatas fue la publicación de La Perinola de Francisco de Quevedo.

17 Plata (2006: 245, nota 1) menciona este hecho para tratar de explicar la animadversión de Quevedo hacia Pérez de Montalbán: la edición espuria del Buscón sufragada por su padre, Alonso Pérez; aunque en realidad, las causas de este enfado pueden tener varios orígenes: fray Diego Niseno, gran amigo de Pérez de Montalbán denunció a la Inquisición el texto quevediano del Chitón de las maravillas y firmó en contra de la publicación de Juguetes.

${ }^{18}$ En este artículo se muestran otros tantos ejemplos de ediciones que lograron salvar la prohibición por parte del Consejo de Castilla de publicar libros "de ocio" entre 1625-1634; por la cantidad de textos que se exponen, los comerciantes de libros encontraron múltiples vías mediante 
Los dos autos sacramentales, Polifemo y Escanderbech se incluyen entre la literatura dedicada al "Quinto día” (Pérez de Montalbán, 1632: fols. 217v-226v y 227r-240v, respectivamente). Los textos están dedicados al padre Diego de Niseno (quien firma la aprobación, junto con Valdivielso), y sin duda el destinatario no es casual: el resto de libros está dedicado a gentilhombres, condes y demás miembros de la corte, mientras que este que contiene las dos piezas de teatro religioso se ofrecen a su mejor amigo y verdadero hombre de $\mathrm{fe}^{19}$. Ensalza sus cualidades humanísticas y sapienciales en los siguientes términos: "solo diré que a V. P. se le ha de alabar por negaciones, que ni es consumado teólogo, ni heroico poeta, ni excelente filósofo, ni acertadísimo escritor, ni predicador soberano, porque lo es todo. Y así, en muestra de que conozco esta verdad, le ofrezco estos dos autos sacramentales..." (1632: fol. 183v).

4. Deleitar aprovechando, de Tirso de Molina, en Madrid, en la Imprenta Real, a costa de Domingo González, 1635.

- Autos: El colmenero divino ${ }^{20}$; Los hermanos parecidos ${ }^{21}$; No le arriendo la ganancia (Delgado Casado, 1996: 342-343).

- Datos de impresión: La Imprenta Real estuvo en funcionamiento desde 1594 hasta el siglo XVIII, en dos locales: parroquia de San Justo y en la Carrera de San Jerónimo. De sus prensas salieron escritos de tipo oficial, y otros relacionados con la familia real, pero además piezas de destacados autores como Nebrija, Cervantes, Góngora, etc. En el caso de Molina, esta institución también fue la encargada de publicar la Quinta parte de comedias, a costa de Gabriel de León, en 1636 (Delgado Casado, 1996: 342-343).

El librero Domingo González tenía su local enfrente de la Trinidad y tal como afirma Pérez Pastor su actividad está acreditada entre los años 16141653. Tuvo un pleito con la Inquisición por atesorar libros prohibidos en 1618. Probablemente muriera poco después de 1647, ya que el último documento que

\footnotetext{
las cuales seguir editando y vendiendo libros. Si bien este contexto rebajaría los beneficios de impresores y mercaderes, una vez levantado el decreto de prohibición, se encontraron con una favorable situación al poder llevar a las prensas todos aquellos títulos que pacientemente habían esperado para ver la luz durante esta década; tal es el caso de la impresora María de Quiñones y el librero Pedro Coello, que en los años posteriores a 1634 publicaron varias Partes de comedias de ingenios áureos como Lope de Vega, Calderón de la Barca o Tirso de Molina. Para ampliar esta información puede consultarse Rodríguez Ortega (2017).

${ }^{19}$ Es necesario recordar que entre ambos existía una profunda amistad; fray Diego de Niseno escribió el Elogio evangélico funeral en el fallecimiento del Doctor Juan Pérez Montalbán, incluido en las Lágrimas panegíricas a la temprana [sic] muerte del gran poeta, y teólogo... Juan Pérez de Montalbán, publicadas en Madrid en 1639 (Grande de Tena, 1639).

${ }^{20}$ Urzáiz Tortajada (2012: 631): "Representado en Sevilla por Pinedo, en 1609 (según otros testimonios, el estreno fue en Toledo, en 1613)".

${ }^{21}$ Urzáiz Tortajada (2012: 631): "Representado en Toledo en 1615".
} 
consta en la lista de sus propiedades librescas entregada al Santo Oficio es de ese mismo año (Agulló y Cobo, 1991: 118-119).

- Sobre la edición: De nuevo se trata de una pieza miscelánea, con intención de publicarse en 1632 (fecha en la que se firma la primera licencia, por el padre Gabriel Adarzo de Santander), aunque no saldrá a la luz hasta 1635, tras el levantamiento de la prohibición y con las aprobaciones de Valdivielso y Jerónimo de la Cruz. Tirso de Molina no tuvo la suerte de Pérez de Montalbán para poder sortear tal ordenamiento y llevar sus obras a las prensas, aunque igualmente trató de cubrir su Deleitar aprovechando de un aura didáctica y religiosa lejana a los textos de comedias, depositarios de esa perjudicial capacidad para modificar el buen comportamiento de las gentes, según los miembros del Consejo de Castilla. Además, es posible recordar que los resultados más amargos de la prohibición tuvieron como destinatarios a Tirso de Molina y Quevedo $^{22}$. En al caso del mercedario, le obligó a abandonar la corte en 1625 y trasladarse a Sevilla, por lo que las consecuencias fueron no solo editoriales sino también personales.

Según recoge Cayuela (1993: 69), en las aprobaciones de la obra tirsiana se insiste en la pulcritud y adecuación de los textos allí recogidos, más próximos a la verdad mediante la narración que al entretenimiento pernicioso de la ficción:

El empleo de este adjetivo "entretenido" parece suscitar una precisión que cobra un sentido particular en el contexto histórico de la acción de la Junta de Reformación sobre la literatura recreativa: "entretenido, sin que en el haya proposición que no sea conforme a la sana doctrina de nuestra $\mathrm{Fe}$, reformación de costumbres". A la reformación de las costumbres también alude Fray Jerónimo de la Cruz cuando declara que Tirso "merece por todos los costados la licencia que a V. A. pide, sin perjuicio de la fe, y costumbres, antes para reformación destas, y confirmación de la otra, etc.”.

En la materia teatral, se decanta Tirso por incluir tres autos sacramentales (y dos diálogos divinos) en esta miscelánea con la que pretende adecuarse a lo esperado por la Junta de Reformación, con tres textos que resultarían a todas luces adecuados. Sin embargo, es posible recordar según afirma Urzáiz Tortajada (2002: 631-632), que las piezas fueron representadas (y escritas) con anterioridad: El colmenero divino en Sevilla en 1609, Los hermanos parecidos en Toledo en 1615 y No le arriendo la ganancia en Madrid en 1614.

$\mathrm{Si}$ leemos con atención la extensa dedicatoria que Tirso le ofrece a don Luis Fernández de Córdoba y Arce, podemos extraer valiosa información para entender el panorama editorial de los autos en el XVII: "Los títulos solos de los libros espirituales dan de suerte en cara, que ofrecerle a un mercader el privilegio de balde, para que los fie al molde, es sentenciarle en la pérdida de gasto y

${ }^{22}$ Esta cuestión ha sido abordada por González Palencia (1946). 
la impresión al destierro de las especerías o cartones (Tan insípida tiene la devoción nuestra tibieza)" (Tirso de Molina, 1635: "Dedicatoria...", s. p.). Como consecuencia, los autos se acompañaban no solo de loas, sino también de entremeses y comedias a lo divino, con la intención de hacer el volumen más completo y atractivo al comprador potencial. De ahí que decida insertar sus autos sacramentales dentro de la miscelánea de 1635.

Para estas cuestiones acerca del negocio del libro en el XVII, los prólogos de Tirso de Molina se nos ofrecen como preciados documentos ${ }^{23}$. Por el contrario, indica el mercedario, las comedias pueden reimprimirse varias veces sin que el impresor y el librero salgan económicamente perjudicados porque el lector no se cansa de ellas. Un último aspecto a comentar, que veremos repetido en otros casos, es la promesa de una segunda parte del Deleitar aprovechando: "No es arrogancia esta promesa del autor, sino excelencia del asunto, léale cualquiera, y si le contentare, dispóngase para la segunda parte, que en breve le prometo" (Tirso de Molina, 1635: “A cualquiera...”, s. p.); no obstante, esta continuación nunca llegó.

5. Fiestas del Santísimo Sacramento, repartidas en doce autos sacramentales, con sus loas y entremeses. Compuestas por el Fénix de España Frey Lope Félix de Vega y Carpio, del hábito de San Juan. Recogidas por el Licenciado Joseph Ortiz de Villena, y dedicadas al túmulo, y fama inmortal suyo, en Zaragoza, por Pedro Vergés, a costa de Pedro Alfay, 1644.

- Autos: Del nombre de Jesús; El heredero del cielo; Los acreedores del hombre ${ }^{24}$; Del pan y del palo ${ }^{25}$; El misacantano; Las aventuras del hombre ${ }^{26}$; La siega; El pastor lobo; La vuelta de Egipto ${ }^{27}$; El niño pastor ${ }^{28}$; De los cantares $^{29}$; La puente del mundo ${ }^{30}$.

- Datos de impresión: El maestro Pedro Vergés imprimió en Zaragoza entre 1624-1645, y también se dedicó a la venta de libros. No destaca por la calidad

${ }^{23}$ Tal es el caso de la Cuarta parte de comedias publicada en 1635, por María de Quiñones, a costa de Pedro Coello, en cuyo prólogo denuncia los abusos en la compra de pliegos del librero Gabriel de León, quien imprimió la Quinta parte de comedias con papel importado; para mayor información puede leerse Rodríguez Ortega (2017).

${ }^{24}$ Urzáiz Tortajada (2012: 684): "BNM, Ms. 15.372, de 1620".

${ }^{25}$ Urzáiz Tortajada (2012: 688): "Estrenado en la corte hacia 1612; constan también representaciones en Sevilla en 1614, por la compañía de Luis de Vergara".

${ }^{26}$ Urzáiz Tortajada (2012: 685): "BNM, Ms. 16.801, con licencia de 1638".

${ }^{27}$ Urzáiz Tortajada (2012: 689): "BNM, Ms. 16.853, del XVII".

${ }^{28}$ Urzáiz Tortajada (2012: 687): "Representado en Sevilla, en 1614, por Hernán Sánchez de Vargas. BNM, Ms. 15.577, del XVII".

${ }^{29}$ Urzáiz Tortajada (2012: 685): "BNM, Ms. 15.228, del XVII".

${ }^{30}$ Urzáiz Tortajada (2012: 688): "Estrenado en Segovia en 1616, por Cristóbal de León, con el título de El puente de Mantible; véase Flecniakoska (1954). BNM, Ms. 15.256". 
de sus impresos, que se consideran "detestables", aunque bien es cierto que además de este volumen de Lope publica otros de Góngora, Quevedo o Francisco Ruiz (Delgado Casado, 1996: 704-705) ${ }^{31}$. Asimismo, también colabora en las Partes XXI, XXII y La vega del Parnaso del Fénix.

Sin información del mercader de libros Pedro Alfei.

- Sobre la edición: Nos encontramos ante un volumen cuidado y preparado con gusto y esmero, que ofrece al lector doce fiestas completas escritas por Lope de Vega: loa, entremés y auto.

Las páginas previas al texto compuestas por el editor Ortiz de Villena no ofrecen información acerca de este volumen, más allá de una continua alabanza de la obra lopesca, esencialmente en cuanto a sus comedias.

6. Autos sacramentales: con cuatro comedias nuevas y sus loas y entremeses: primera parte, en Madrid, por María de Quiñones, a costa de Juan de Valdés, $1655^{32}$.

- Autos: El reino en cortes y rey en campaña: auto sacramental ${ }^{33}$, de Coello; Auto de las plantas ${ }^{34}$, de Calderón de la Barca; Famoso auto sacramental del gran

31 Moll (1992: s. p.) amplía la información al respecto: "Pedro Vergés, librero de Madrid, probablemente emparentado con el homónimo impresor zaragozano y que como hemos visto coeditó la parte XXII con Domingo de Palacio y Villegas, decidió continuar la colección de Lope. Existiendo herederos en los reinos de Castilla, no consideraría fácil obtener privilegio en los mismos y lo obtuvo para el reino de Aragón a favor del impresor zaragozano Pedro Vergés, por diez años, dado en Zaragoza el 17 de octubre de 1640. Es la parte XXIV, impresa en dicha ciudad el año 1641. La intervención del librero Pedro Vergés se expresa en la dedicatoria a Don Bernardo de Velasco y Rojas, secretario del Secreto del Santo Oficio de la Inquisición del Reino de Aragón, fechada en Madrid, el 12 de agosto de 1641, en la que explícitamente se declara que «se han impreso a mi costa». Quizás también intervino en la preparación de esta parte José Ortiz de Villena, pues le vemos colaborar con el mismo librero de Madrid, Pedro Vergés, tres años después, al recopilar los autos sacramentales que formarán las «Fiestas al Santissimo Sacramento» ${ }^{1}$, también impresas en Zaragoza por el impresor Pedro Vergés, «A costa de Pedro Vergés, Mercader de Libros, en la calle de Toledo», de Madrid. Esta obra fue coeditada con el librero zaragozano Pedro Alfay, existiendo otra emisión en la que figura «A costa de Pedro Alfai, Mercader de libros»" (1992: s.p.).

32 Este volumen, al igual que las dos publicaciones que le suceden cronológicamente, se acompañan de piezas pertenecientes a otros géneros: comedias, loas, entremeses, etc., porque según parece, la impresión exclusiva de autos sacramentales no resultaría rentable. Solo en los casos de Calderón y Valdivielso (aunque no en sentido estricto ya que contiene dos comedias a lo divino), el autor decide llevar a las prensas sus piezas sacramentales. De cualquier modo, ambos escritores probablemente estarían convencidos de la calidad de sus escritos y de la necesidad de confirmar su autoría. No en vano son dos de los compositores de autos más sobresalientes. En el caso de Lope, además del auto se compila la fiesta completa, pero como hemos visto, la decisión de publicarlos no fue del Fénix sino de su gran amigo Ortiz de Villena.

${ }^{33}$ De esta obra existe una edición crítica inédita preparada por Garrot Zambrana.

34 Se trata de La humildad coronada, según el autógrafo calderoniano (fechado en 1644), aunque existe otra variación del título en la edición de Pando en 1717, La humildad coronada de las plantas; como recoge Arellano en el estudio textual del auto (Arellano y Duarte, 2003: 141-142), 
patio de palacio $^{35}$ [Rojas Zorrilla]; Auto sacramental de los obreros del señor ${ }^{36}$, de Rojas Zorrilla; Auto sacramental del pleito matrimonial del cuerpo y el alma ${ }^{37}$, de Calderón de la Barca; Coloquio primero de los pastores de Belén ${ }^{38}$, de Godínez; Auto sacramental del galán discreto y valiente, de Rojas Zorrilla; Coloquio del nacimiento de nuestro señor, de Mira de Amescua; Auto sacramental, El cubo de la Almudena ${ }^{39}$, de Calderón de la Barca; Auto del heredero, de Mira de Amescua; Las pruebas de Cristo ${ }^{40}$, de Mira de Amescua; Auto del nacimiento, de Vélez de Guevara; Auto sacramental, El teatro del mundo, de Calderón de la Barca.

Comedias $^{41}$ : La Virgen de Guadalupe ${ }^{42}$, de Felipe Godínez; El prodigio de los montes y mártir del cielo ${ }^{43}$, de Guillén de Castro; El gran rey de los desiertos, de Andrés de Claramonte; El rico avariento, de Mira de Amescua.

la pieza es nombrada Auto de las plantas en todas las copias del XVII que se conservan, a excepción de una, en el volumen de autos de 1675 en que se atribuye a Rojas Zorrilla. Urzáiz Tortajada (2012: 199): "Autógrafo fechado el 17 de marzo de 1644 (BNM, Ms. Res. 72); representado ese año en el Corpus toledano".

${ }^{35}$ Urzáiz Tortajada (2002: 474) afirma que es de Rojas Zorrilla. También "Escrito en 1647 y representado por Osorio. Hay dos manuscritos del XVII, uno en la BNM (Ms. 15.132, atribuido a Calderón en la primera hoja) y otro en la MLG (44-Caja-15.584, M. 38/31)" (Urzáiz Tortajada, 2012: 573).

${ }^{36} \mathrm{El}$ auto es de Calderón, quien se lo atribuye a sí mismo en uno de los documentos más fidedignos que confirman la autoría calderoniana, la lista que envió al duque de Veragua; afirma Vega García-Luengos (2008: 249, nota 2) que también existe otro escrito de estas características: "La primera fue presentada al monarca por Francisco Marañón, Secretario del Patriarca de las Indias, y nos ha llegado en una copia manuscrita del siglo XVIII (BNE: MS 10.838, fol. 288r-290r), que publicó Wi1son, 1962-1963. La segunda fue enviada a Pedro Manuel Colón de Portugal, VII duque de Veragua, en una carta. Gaspar Agustín de Lara la incluyó en el Obelisco fúnebre, pirámide funesto a la inmortal memoria de D. Pedro Calderón de la Barca... (Madrid, Eugenio Rodríguez, 1684)". También debemos a Vega García-Luengos (2003) un amplio estudio sobre la situación de los impresos en el siglo XVII español. Insúa y Mata Induráin (2013) han realizado la edición crítica del auto La siembra del señor. Urzáiz Tortajada (2012: 202): "BNM, Ms. 16.280".

${ }^{37}$ Urzáiz Tortajada (2012: 201): "fue representado en Sevilla en 1651, por Francisco de Castro. BNM, Ms. 16.2817".

${ }^{38} \mathrm{Al}$ igual que en el caso de Mira de Amescua, comprobamos la laxitud del editor al recoger los títulos para un volumen de autos sacramentales, en el que se incluyen dos coloquios; estos últimos tienen un carácter más sencillo, mayor brevedad, menor número de personajes y se presentan de forma dialogada.

${ }^{39}$ Urzáiz Tortajada (2012: 197): "Representado en 1651".

${ }^{40}$ Urzáiz Tortajada (2012: 452): "Representado en Sevilla, en 1631, por la compañía de Bartolomé Romero. Manuscrito de 1630, de mano del librero Martínez de Mora (BNM, Ms. 16.690)".

${ }^{41}$ No se acompañan del calificativo "divino", como sí sucede en la edición de Valdivielso, aunque igualmente tratan de temas bíblicos y hagiográficos,

${ }^{42}$ Se trata de comedia y no auto, según indica el volumen editado por Antonio Francisco de Zafra, en 1675, que examinaremos más adelante. Así aparece en la edición sevillana a cargo de Manuel Nicolás Vázquez; además, teniendo en cuenta razones más pragmáticas, de este modo resultan los cuatro títulos de comedias de esta compilación.

${ }^{43}$ Existen dudas acerca de la autoría de esta pieza: en este volumen y en dos sueltas, se atribuye la comedia a Guillén de Castro, pero Vega García-Luengos (2010) "localiza dentro de una 
- Datos de impresión: La impresora María de Quiñones trabajó en Madrid, en la imprenta heredada de Pedro Madrigal y ubicada en la calle Atocha entre aproximadamente 1633 hasta 1666. No se puede confirmar la fecha exacta en que se hace cargo del taller, puesto que en los años anteriores a 1633 se utiliza la rúbrica "Viuda de Pedro Madrigal" o "Herederos de Pedro Madrigal". Junto con el librero Pedro Coello editó varias partes de comedias de ingenios auriseculares como Tirso, Lope o Calderón ${ }^{44}$.

El librero Juan de Valdés trabajaría en Madrid en el periodo de 1640 a $1676^{45}$. Fue propietario de un beneficioso negocio y como otros tantos libreros de la época, compraba el papel a los cartujos segovianos del Paular; los documentos de estas transacciones atestiguan el intenso trabajo de su taller. Formó parte de la Hermandad de Libreros entre 1647-1666 (Agulló y Cobo, 1991: 322-323).

- Sobre la edición: Una de las primeras características de este volumen que llama la atención es la ausencia de piezas sacramentales lopianas, lo que probablemente se deba a la publicación de las Fiestas del Santísimo Sacramento recogidas por Ortiz de Villena que vieron la luz la década anterior. Sin embargo, nos movemos en el terreno de la suposición puesto que ninguna información sobre el proceso editorial puede extraerse de la dedicatoria del libro a don Francisco de Camargo y Paz, caballero de la orden de Santiago.

No existen mayores cuestiones relativas a la publicación de este tomo, que se realiza con la precisión y esmero de Quiñones, quien inserta una tabla de contenidos en que diferencia comedias, autos, loas y entremeses, aunque en la pieza se encuentren mezclados. De este modo, sería más fácil ubicar cada título en sus páginas correspondientes, aunque también podemos extrapolar este hecho a una cuestión de preponderancia editorial: las comedias serían más importantes que los autos, y estos que las loas y entremeses. Los autores cuyas obras se compilan en este volumen no se han dejado al azar:

La recopilación, desde luego, es muy inteligente desde un punto de vista comercial si tenemos en cuenta, además, que los nombres que avalan el libro son los mismos de los ingenios que habían conocido una consagración en años precedentes gracias a las partes colectivas de comedias: desde Guillén de Castro hasta Calderón de la Barca y Francisco de Rojas Zorrilla, pasando por Andrés de Claramonte, Antonio Mira de Amescua o Luis Vélez de

\footnotetext{
amplísima colección de sueltas no catalogadas en la BNE una del siglo XVII, que perteneció a Durán, en que se atribuye a Calderón y Tomé de Miranda, con lo que se refuerza una atribución a Calderón bastante difundida en la bibliografía".

${ }^{44}$ Para ampliar la información sobre esta impresora madrileña y la historia de su imprenta desde los tiempos del primer Pedro Madrigal, puede consultarse Rodríguez Ortega (2017).

${ }^{45}$ Aunque Agulló y Cobo (1991: 352) afirma que esta información es errónea, sin aportar más datos.
} 
Guevara (además de Jerónimo de Cáncer o Agustín Moreto para los entremeses) tienen su hueco en el nuevo lanzamiento editorial promovido por Juan de Valdés (Gómez Sánchez-Ferrer, 2015: 503).

7. Navidad y Corpus Christi, festejados por los mejores ingenios de España en diez y seis autos a lo divino, diez y seis loas y diez y seis entremeses: representados en esta corte y nunca hasta ahora impresos, en Madrid, por Joseph Fernández de Buendía, a costa de Isidro de Robles, 1664.

- Autos: Auto famoso El divino Jasón ${ }^{46}$, de Calderón de la Barca; Auto famoso La mayor soberbia humana de Nabucodonosor, de Mira de Amescua; Auto famoso La mesa redonda ${ }^{47}$, de Vélez de Guevara; Auto famoso del Nacimiento del hijo de Dios, el tirano castigado ${ }^{48}$, de Lope de Vega; Auto famoso del Premio de la limosna y rico de Alejandría, de Felipe Godínez; Auto famoso del Caballero del $F_{e b o}{ }^{49}$, de Rojas Zorrilla [Pérez de Montalbán]; Auto famoso sacramental de Las santísimas formas de Alcalá ${ }^{50}$, de Pérez de Montalbán; Auto famoso del Nacimiento de Cristo, nuestro bien y sol a media noche, de Mira de Amescua; Auto famoso sacramental de La gran casa de Austria y divina Margarita ${ }^{51}$, de Moreto; Auto famoso sacramental Entre día y noche, de Valdivielso; Auto famoso sacramental La cena del Rey Baltasar ${ }^{52}$, de Calderón de la Barca; Auto famoso de Nuestra Señora del Rosario, la madrina del cielo ${ }^{53}$, de Tirso de Molina; Auto famoso de Nuestra Señora del Rosario, ciento por uno, de Cubillo de Aragón; Auto famoso del Nacimiento de Nuestro Señor, de Valdivielso; Auto famoso del Nacimiento de Nuestro Salvador Jesucristo ${ }^{54}$, de Lope de Vega.

- Datos de impresión: Fernández de Buendía fue librero del rey entre 1658 y 1681 (según Gutiérrez del Caño, cit. en Agulló y Cobo, 1991: 94), aunque la firma "Viuda de Fernández de Buendía" aparece por primera vez en 1680. Según consta, su taller se ubicaba en Madrid, en la calle del Duque de Alba.

El librero Isidro de Robles procedía de una importante familia dedicada al

46 Urzáiz Tortajada (2012: 197): "BNM, Ms. 16.279”.

${ }^{47}$ Urzáiz Tortajada (2012: 707): "Representado en Sevilla por la compañía de Juan Jerónimo Valenciano, en 1633. BNM, Ms. 17.402".

${ }^{48}$ Existe una comedia homónima escrita en 1599 que vio la luz en 1614 (Urzáiz Tortajada, 2002: 682).

49 En realidad se trata de un auto de Pérez de Montalbán; se conservan varias copias de un manuscrito con fecha de 1631 (Urzáiz Tortajada, 2002: 514).

${ }^{50}$ Urzáiz Tortajada (2002: 514): "Escrito hacia 1623. Manuscrito autógrafo en parte, firmado en la última BNM, Ms. 15.237, de mano de Martínez de Mora hoja (BNM, Ms. Vit-7-8)".

${ }^{51}$ Urzáiz Tortajada (2002: 474): "BNM, Ms. 15.237, de mano de Martínez de Mora".

52 Urzáiz Tortajada (2002: 197): "BNM, Ms. 16.282. Un auto sacramental con este título fue representado en Sevilla, en 1634, por la compañía de Pedro de Ortegón, aunque Sentaurens (1115) cita a Luis Vélez de Guevara como posible autor".

${ }^{53}$ Urzáiz Tortajada (2002: 631) duda de la autoría tirsiana del auto.

${ }^{54}$ Urzáiz Tortajada (2002: 687): "Representado en Madrid". 
negocio y fue hijo de Sebastián de Robles y Magdalena de Aragón. Asentó su negocio primero en la calle Toledo, junto a la Compañía de Jesús (16321651) y después en la calle Mayor. Formó parte de la Hermandad de Libreros entre 1646-1660 (Agulló y Cobo, 1991: 268-269).

- Sobre la edición: Por primera vez, un volumen de autos nos ofrece un panorama amplio del conjunto de autores que se dedicaron al género: Cubillo de Aragón, Lope de Vega o Valdivielso no contaron con presencia alguna en la edición de 1655, a pesar de ser estos dos últimos escritores prolíficos de piezas sacramentales. Los diferentes epígrafes en los que se divide la publicación y que vienen recogidos en el índice nos dan muestra de la singularidad de la pieza: "Loas famosas de los mejores ingenios de España", "Entremeses famosos compuestos por Luis de Benavente" y "Autos sacramentales y del nacimiento de Cristo nuestro Señor y de nuestra Señora de Rosario". Se establece una diferencia entre los autos sacramentales y aquellos tan frecuentes también dedicados en concreto al nacimiento de Cristo, y más cercanos en desarrollo y complejidad a los misterios medievales. Asimismo, se incluye la mención a la Virgen del Rosario, para dar cabida al auto de temática mariana atribuido a Tirso de Molina. De este modo, "encubierto" en un volumen de loas y autos sacramentales, hallamos un importante proyecto editorial de los entremeses de Luis Quiñones de Benavente, del que se incluyen dieciséis creaciones.

El tomo se dedica al licenciado don García de Velasco e incorpora en su título la llamativa frase "representados en esta corte y nunca hasta ahora impresos", para destacar que nos encontramos ante una impresión inédita. Y de hecho, la comprobación resulta favorable si lo comparamos con el volumen de 1655 pues no coinciden en un solo título. Además, como hemos cotejado, el corpus de autores es ahora más amplio, y por tanto, constituye un documento bibliográfico más próximo a la realidad literaria de aquel momento. Es de suponer que el librero Fernández de Buendía gozaría de buenos y numerosos contactos que pudieran facilitarle el acceso a estos títulos.

Según se recoge en la dedicatoria, este sería la primera compilación de textos realizada por Isidro de Robles, quien aparte de ejercer como librero fue el editor del volumen: "El primero libro que a mis expensas sale a la luz común, debo a V. M. como al primero acreedor en mis obligaciones..." (Navidad y Corpus Christi, 1664: fol. 2). Los textos no provendrían de "sueltas", pues se insiste en el carácter inédito, sino que Robles habría accedido a los originales manuscritos.

8. Autos sacramentales y al nacimiento de Cristo: con sus loas y entremeses, en Madrid, por Antonio Francisco de Zafra, a costa de Juan Fernández, 1675.

- Autos: Auto sacramental del galán, discreto y valiente; de Rojas Zorrilla; [Auto sacramental del galán discreto y valiente; de Rojas Zorrilla, 1655]; Fa- 
moso auto sacramental del gran palacio; de Moreto; [Famoso auto sacramental del gran patio de palacio; de Rojas Zorrilla, 1655]; Las pruebas de Cristo; de Mira de Amescua; [Las pruebas de Cristo; de Mira de Amescua, 1655]; Auto del nacimiento de Cristo; de Vélez de Guevara; [Auto del nacimiento; de Vélez de Guevara, 1655]; Auto del nacimiento de Cristo y pastores de Belén; de Godínez; [Coloquio primero de los pastores de Belén; de Godínez, 1655]; Auto del nacimiento de Cristo; de Godínez; Auto del nacimiento de Nuestro Señor; de Mira de Amescua; [Coloquio del nacimiento de nuestro señor; de Mira de Amescua, 1655]; Auto sacramental del heredero; de Mira de Amescua; [Auto del heredero; de Mira de Amescua, 1655]; Auto sacramental de La Virgen de Guadalupe; de Godínez; [Comedia La Virgen de Guadalupe; de Godínez, 1655]; Auto a Nuestra Señora del Pilar; de Felipe Sánchez; Auto sacramental; del licenciado don Diego Ramos del Castillo; Auto sacramental; del licenciado don Diego Ramos del Castillo; Auto sacramental; del licenciado do Diego Ramos del Castillo; Auto sacramental al nacimiento del hijo de Dios; de Antonio de Castilla; Auto sacramental de los árboles; de Rojas Zorrilla; [Auto de las plantas; de Calderón de la Barca, 1655] $]^{55}$.

- Datos de impresión: El impresor Zafra fue criado del rey y trabajó en Madrid entre 1675-1695. Se supone que tenía el taller en la calle Las Negras, pues su mujer lo heredó en 1706 (Agulló y Cobo, 1991: 339).

Juan Fernández, fue un librero madrileño cuyo negocio se ubicaba en la calle de Toledo, junto a la Compañía de Jesús. Fue tesorero de la Hermandad de San Jerónimo entre 1701-1712 (Agulló y Cobo, 1991: 339).

- Sobre la edición: El volumen Autos sacramentales y al nacimiento de Cristo: con sus loas y entremeses de 1675, según puede apreciarse en la descripción de los títulos y su correspondencia indicada seguidamente, muestra una gran cantidad de coincidencias con la edición de 1655 impresa por Quiñones y vendida en casa de Juan de Valdés.

Se elimina el primer auto del tomo de 1655 a cargo de Coello, además del Auto sacramental de los obreros del señor, Auto sacramental del pleito matrimonial del cuerpo y el alma, Auto sacramental, El cubo de la Almudena y el Auto sacramental, El teatro del mundo. Los cuatro son títulos fruto de la pluma calderoniana, aunque el primero de ellos estuviera atribuido a Rojas Zorrilla en la publicación precedente ${ }^{56}$. Sin embargo, sabían entonces y sabemos ahora que el autor de la pieza fue Calderón de la Barca. La razón de esta reducción fue la puesta en marcha de un proyecto editorial a cargo del dramaturgo madrileño. Ruano de la Haza (1995: 61-62) explica esta situación:

${ }^{55}$ Ya hemos visto que se trata de La humildad coronada de Calderón, aquí falsamente atribuida a Rojas Zorrilla.

${ }^{56}$ Cienfuegos (2016) ofrece un esencial estudio de la cuestión respecto a los autos del dramaturgo toledano. 
Es probable, pues, que Calderón realizara las copias en limpio entre 1665 y 1670 (más de diez años antes de recibir la carta el duque de Veragua); que los entregara a un impresor o al Ayuntamiento de Madrid [...] Libre, pues, de sus obligaciones de escribir para la corte, es posible que Calderón encontrara tiempo para pasar en limpio los 23 autos que se conservan autógrafos en la Biblioteca Histórica de Madrid ${ }^{57}$.

Como consecuencia, la impresión de Zafra respeta los autos de Calderón, que ya está editando el propio autor para vendérselos al ayuntamiento de Madrid, y no los incluye en este tomo colectivo. No obstante, aunque supuestamente no lo hubieran constatado, sí contiene un texto calderoniano, el Auto sacramental de los árboles, que en realidad es La humildad coronada. También se confunde el texto de Godínez, La Virgen de Guadalupe, comedia a lo divino en la edición de 1655; es posible que el título despistara al librero y al impresor y creyeran que se trataba de un auto sacramental (recordemos que Godínez también había escrito este tipo de piezas). Con esta atribución se publica en 1675, sin tener en cuenta que el ejemplar de 1655 además de autos contenía cuatro comedias, entre ellas la del escritor onubense.

Por otro lado, se añaden obras de tres autores poco conocidos: Felipe Sánchez $^{58}$, Diego Ramos del Castillo y Antonio de Castilla ${ }^{59}$. Tres autos del licenciado tinerfeño Ramos del Castillo ${ }^{60}$ nos ofrece esta obra colectiva, una llamativa presencia de un autor casi desconocido entre los grandes dramaturgos áureos. Como consecuencia, es fácil pensar que el impresor o el librero poseía algún tipo de cercanía con el licenciado canario para ser los receptores de la totalidad de su obra sacramental, que no se ha publicado en ninguna otra ocasión.

Finalmente, un breve repaso al único paratexto que firma el librero: la dedicatoria a don Diego Pérez de Orejón, secretario del rey, en la que aparte del lenguaje y contenido laudatorio de este tipo de literatura, no encontramos mención alguna al propósito editorial del libro ni al volumen de 1655 de donde habría sacado al menos la mitad de sus textos.

57 En una investigación reciente también asevera: "Estos manuscritos, excepcionalmente en tamaño folio, en contra de su práctica usual de escribir en papel tamaño cuarto, son copias en limpio, sacadas por el mismo Calderón con la intención de enviarlas a la imprenta" (Ruano de la Haza, 2015: 2).

58 Urzáiz Tortajada (2002: 598) opina que puede tratarse de Felipe Sánchez Carralero; de cualquier modo, toda la obra atribuida a este autor es la que aparece en el volumen de 1675: dos loas y un auto.

${ }^{59}$ Escritor de autos sacramentales (Urzáiz Tortajada, 2002: 231), uno de ellos en esta edición, y todos ellos publicados en 1675 .

${ }^{60}$ Existe una investigación monográfica acerca de su obra y vida, gracias a la cual sabemos que aparte de estos tres autos también compuso poesía para ser cantada (Rodríguez Morales, 2008). Estas tres piezas sacramentales se encuentran inéditas, por lo que en sucesivos trabajos me dedicaré a su edición crítica. 
9. Autos sacramentales alegóricos y historiales. Primera parte, de Pedro Calderón de la Barca. En Madrid, en la Imprenta Imperial, por Joseph Fernández de Buendía, y a su costa, $1677^{61}$.

- Autos: Las órdenes militares ${ }^{62}$; El santo rey don Fernando (primera parte) ${ }^{63}$; El santo rey don Fernando (segunda parte) ${ }^{64}$; La vida es sueño ${ }^{65}$; El divino Orfeo ${ }^{66}$; Primero y segundo Isaac ${ }^{67}$; La nave del mercader; La viña del Señor ${ }^{68}$; La vacante general ${ }^{69}$; Quién hallará mujer fuerte ${ }^{70}$; No hay instante sin milagro $^{71}$; El nuevo hospicio de pobres $^{72}$.

- Datos de impresión: No constan datos acerca de la Imprenta Imperial, más allá de que estuvo a cargo de Fernández de Buendía al menos entre 1676-1679.

La información sobre Fernández de Buendía aparece en la descripción del volumen Navidad y Corpus Christi.

- Sobre la edición: Se trata de la única edición publicada en vida del poeta y autorizada por él mismo; no solo esta circunstancia permite atestiguar la autoría de las piezas sacramentales aquí incluidas, sino que el "Prólogo al lector" calderoniano es una fuente inestimable como testimonio del contexto editorial en que se inserta el volumen.

Ya en las primeras líneas se hace latente la inclinación (casi obsesión) calderoniana por reescribir sus obras, a las que considera aquí "mal limados borradores", lo que constituye aparte de una muestra de captatio benevolentiae, un ejemplo de su constante proceso de perfeccionamiento (tan importante o

${ }^{61}$ Garrot Zambrana (s. f.) ha realizado una edición electrónica de este prólogo.

${ }^{62}$ Urzáiz Tortajada (2002: 200): "Representado el 25 de junio de 1662 en el corral del Príncipe, por la compañía de Simón Aguado. Autógrafo fechado en 1662 (BNM, Ms. Res. 24)”.

${ }^{63}$ Urzáiz Tortajada (2002: 202): "Representado en 1671, para conmemorar la canonización de Fernando III'.

${ }^{64}$ Urzáiz Tortajada (2002: 202): "Representado en 1671, para conmemorar la canonización de Fernando III".

${ }^{65}$ Urzáiz Tortajada (2002: 203): "Representado en 1673, junto con la mojiganga de La muerte. BNM, Ms. 16.713".

${ }^{66}$ Urzáiz Tortajada (2002: 197): "Escrito hacia 1634. BNM, Ms. 16.278" (primera versión).

${ }^{67}$ Urzáiz Tortajada (2002: 201): "Representado en 1658".

${ }^{68}$ Urzáiz Tortajada (2002: 203): "Representado en 1674, por las compañías de Simón Aguado y Manuel Vallejo".

${ }^{69}$ Urzáiz Tortajada (2002: 203): "Representado en 1649 por la compañía de Prado".

${ }^{70}$ Urzáiz Tortajada (2002: 201): "Representado en 1672, junto con el entremés de El escolar y el soldado, por la compañía de Escamilla”.

71 Urzáiz Tortajada (2002: 200): "Representado en Madrid en 1672; también en Sevilla, en 1677, por la compañía de Magdalena López”.

${ }^{72}$ Urzáiz Tortajada (2002: 200): "Representado en el corral de la Cruz en junio de 1675, por la compañía de Manuel Vallejo, aunque la fecha de redacción podría ser varios años anterior (el hospicio de la congregación del Dulce Nombre de María se fundó en 1668, en mitad de la prohibición de representar autos entre 1666-1669)". 
más que el expresar su humildad frente al lector, aunque más que falsa modestia podría entenderse como confesión). Si es bien sabida la dispersa fortuna de las comedias impresas: sueltas, espurias, contrahechas, mal atribuidas, deturpadas, etc., los autos sacramentales no se hallaban ajenos a estas vicisitudes, aunque suponemos que en menor medida por el interés comercial inferior que presentaban. Y Calderón no solo expresa las perniciosas consecuencias que tienen para los autores, sino también para aquellos que se favorecen de las ganancias económicas: obras pías y hospitales (solían gestionar los corrales de comedias).

Este es el entorno vigente por el que Calderón decide llevar a la imprenta un corpus de autos sacramentales acompañados de sus loas. Por último, el dramaturgo madrileño nos aporta información que sirve para completar el panorama editorial de los autos ya trazado por Tirso cuando corroboraba que el librero que se decidiese a sufragar la impresión de autos no obtendría pingües beneficios. La razón de que los autos no se demandaran es que apenas se leían: perdían gran parte de su atractivo en la página impresa y fuera del contexto festivo del Corpus Christi. Calderón (1677: "Al lector", s. p.) lo expresa en el tan conocido pasaje: "Parecerán tibios algunos trozos, puesto que el papel no puede dar de sí, ni lo sonoro de la música, ni lo aparatoso de las tramoyas; si ya no es que el que los lea haga en su imaginación composición de lugares, considerando lo que sería sin entero juicio de lo que es, que muchas veces descaece el que escribe de sí mismo por conveniencias del pueblo o del tablado".

Finalmente, al igual que Tirso, menciona una continuación de su proyecto que resultaría inédito, al menos en versión impresa, pero no manuscrita. Según hemos comentado con anterioridad, a partir de 1665 Calderón comenzó la puesta en limpio de sus autos, un conjunto de ellos aparecen en la edición impresa de 1677 , mientras que el resto se conservan en los autógrafos originales en la Biblioteca Histórica de Madrid.

\section{CONCLUSIÓN}

En resumen, la publicación de autos sacramentales durante el siglo XVII en España está marcada por una clara tendencia: la falta de interés de los autores por llevar a la imprenta sus piezas religiosas. Según hemos visto, solo dos autores (aunque de los más sobresalientes en el género), Valdivielso y Calderón, prepararon sus textos para su edición en papel. Podemos suponer que sería difícil para el lector de teatro del Siglo de Oro español imaginar los autos fuera del tejido festivo del Corpus Christi, donde la intensa escenografía, la música y el sentimiento de comunión religiosa construían el marco donde este tipo de dramaturgia encajaba a la perfección. Justamente con ese horizonte en perspectiva los textos sacramentales habían sido creados. Incluso su representación fue- 
ra de estas fechas habría afectado a su sentido más profundo, la exaltación de la Eucaristía en su día señalado ${ }^{73}$.

Tampoco debemos olvidar que nos encontramos ante versos de difícil lectura y comprensión, plagados de glosas bíblicas, referencias intertextuales, alusiones bíblicas, etc. que el lector no instruido no sería capaz de comprender, mucho menos de divertirse. Es posible recordar que la inmensa mayoría del público lector en el Siglo de Oro buscaba el entretenimiento en la página escrita; para cuestiones de fe ya acudía a la iglesia.

Teniendo en mente esta realidad, resulta más fácil comprender la razón por la que los poetas no publicaron sus autos: apenas dos ediciones en vida, una póstuma, dos en misceláneas, etc., además de emplazamiento a segundas partes que nunca vieron la luz. Eran conscientes de que no despertarían el interés del público y, por tanto, su traspaso al papel no resultaría un negocio provechoso para impresores y libreros. Sin embargo, existe este breve pero esencial corpus de autos publicados durante el Siglo de Oro español, que de manera personal o póstuma, individual o colectiva, nos permiten hoy examinar las piezas religiosas de los grandes autores auriseculares. Por ejemplo, en el caso de Lope, únicamente presentan una atribución segura los aquí reseñados: la edición de Ortiz Villena y los textos incluidos en El peregrino (fruto de un razonado proyecto editorial, según explicaba Avalle-Arce). También resultan interesantes los esfuerzos de Pérez de Montalbán y Tirso de Molina para publicar autos durante la época de prohibición, recurriendo a aquellos textos más cercanos a la fe para lograr la aprobación del Consejo; y los tres volúmenes colectivos, que de un modo "objetivo" nos detallan el entramado de autores y obras disponibles para la impresión en tres momentos diferentes del siglo XVII. Para concluir, una sucinta mención a los dos autores que por propia iniciativa decidieron llevar sus textos a la imprenta, tras dedicarle una buena cantidad de tiempo y pulir y perfeccionar los originales.

Por último, es necesario recordar la recurrencia de los escritores de autos al mismo asunto, la Eucaristía, al situarse como epicentro mismo de la festividad del Corpus en la que se integra la representación. Pero no solo eso, sino que además recreaban con frecuencia los mismos pasajes bíblicos (parábola del sembrador, del hijo pródigo...) o personajes mitológicos (Psique y Cupido, Jasón, Orfeo.... $)^{74}$. Como consecuencia, los autos sacramentales no deparaban al

${ }^{73} \mathrm{Sin}$ embargo, es necesario recordar que las capitales de provincia fuera de los grandes núcleos (Sevilla, Toledo, Madrid, Valladolid, Granada, etc.) solo podrían disfrutar de estas representaciones en fechas distintas a las del Corpus. Aquellas compañías teatrales que contaban con autos dentro de su repertorio, seguían poniéndolos en escena durante el resto del año en otras localidades, que si bien podían contemplar parte del espectáculo, carecían insalvablemente de todo el marco festivo y religioso de la situación primigenia.

${ }^{74}$ Urzáiz Tortajada (2000) ha estudiado el fenómeno de reescritura y reelaboración tan propio, por ejemplo, de Calderón, a propósito del auto La orden de Melquisedech del dramaturgo madrileño. 
lector mucha sorpresa ${ }^{75}$ ni variedad temática ni argumental, de modo que no resultarían tan atrayentes como las comedias.

Este cúmulo de razones aludidas son la causa por la que los volúmenes dedicados a los autos en el siglo XVII, momento de su máximo esplendor creativo, son tan exiguos. No obstante, por la rareza de su existencia y la diferencia entre sus condiciones de edición, resulta interesante realizar un análisis de las condiciones particulares de estos impresos para ampliar el paisaje existente en la investigación hasta la actualidad de los estudios sobre la publicación de libros en el Siglo de Oro español.

\section{BIBLIOGRAFÍA}

Agulló y Cobo, Mercedes (1991): La imprenta y el comercio de libros en Madrid (siglos XVIXVIII), tesis doctoral, Madrid, Universidad Complutense de Madrid.

Arellano, Ignacio y J. Enrique Duarte (2003): El auto sacramental, Madrid, Laberinto.

Autos sacramentales con cuatro comedias nuevas y sus loas y entremeses. Primera parte (1655): Madrid, por María de Quiñones, a costa de Juan de Valdés.

Autos sacramentales y al nacimiento de Cristo: con sus loas y entremeses (1675): Madrid, por Antonio Francisco de Zafra, a costa de Juan Fernández.

Avalle-Arce, Juan B. (ed.) (1973): Lope de Vega, El peregrino en su patria, Madrid, Castalia.

Calderón de la Barca, Pedro (1677): Autos sacramentales alegóricos y historiales. Primera parte, Madrid, en la Imprenta Imperial, por Joseph Fernández de Buendía, y a su costa.

Cayuela, Anne (1993): "La prosa de ficción entre 1625-1634. Balance de diez años sin licencias para imprimir novelas en los reinos de Castilla", Mélanges de la Casa de Velázquez, XXIX, 2, pp. 51-76.

Cayuela, Anne (2005): Alonso Pérez de Montalbán. Un librero en el Madrid de los Austrias, Madrid, Calambur.

Cienfuegos Antelo, Gemma (2016): "Los autos sacramentales de Rojas Zorrilla: consideraciones acerca del repertorio y su representación”, en Rafael González Cañal (ed.), El universo dramático de Rojas Zorrilla, Valladolid, Ediciones Universidad de Valladolid, Colección Fastiginia, 11 , pp. $79-90$.

Delgado Casado, Juan (1996): Diccionario de impresores españoles: siglos XV-XVII, 2 vols., Madrid, Arco/Libros.

Duarte, Enrique (2013): "Microestructuras en los autos sacramentales de José de Valdivielso: un camino hacia Calderón", en Bruno Vargas y Vincent Marin (eds.), Le pouvoir de l'opinion publique/Micro-récits et frontières dans les textes espagnols du Siècle d'Or, <https:// framespa.revues.org/2393>.

García Reidy, Alejandro (2013): Las musas rameras. Oficio dramático y conciencia profesional en Lope de Vega, Madrid/Frankfurt, Iberoamericana/Vervuert.

Garrot Zambrana, Juan Carlos (s. f.): "Autos sacramentales... (Calderón de la Barca, Pedro): Préface", <http://www.idt.paris-sorbonne.fr/html/Calderon-Sacramentales-Preface.html .

75 Tanto lectores como espectadores sabrían con certeza que a pesar de los múltiples intentos del demonio (en cada una de sus diversas representaciones), únicamente hallaría el fracaso, en detrimento de la victoria de Cristo. 
Gómez Sánchez-Ferrer, Guillermo (2015): Del corral al papel: estudio de impresores españoles de teatro en el siglo XVII, tesis doctoral inédita, Madrid, Universidad Complutense de Madrid.

González Palencia (1946): "Quevedo, Tirso y las comedias ante la Junta de Reformación”, Boletín de la Real Academia Española, XXV, pp. 43-84.

Grande de Tena, Pedro (ed.) (1639): Lagrimas panegíricas a la temprana [sic] muerte del gran poeta, y teólogo... Juan Pérez de Montalbán, Madrid, en la Imprenta del Reino.

Insúa, Mariela y Carlos Mata Induráin (eds.) 2013: Pedro Calderón de la Barca, La siembra del Señor (Los obreros del Señor), Pamplona/Kassel, Universidad de Navarra/Reichenberg.

Marcello, Elena E. (s. f.): "Doce autos sacramentales y dos comedias divinas (Valdivielso, José de): Préface", <http://www.idt.paris-sorbonne.fr/html/Valdivielso-DoceAutos-Preface.html>.

Moll, Jaime (1992): "De la continuación de las partes de comedias de Lope de Vega a las partes colectivas", en Homenaje a Alonso Zamora Vicente, Madrid, Castalia, t. 3, 2, pp. 199-211, $<\mathrm{http}$ //www.cervantesvirtual.com/obra-visor/de-la-continuacion-de-las-partes-de-comedias-delope-de-vega-a-las-partes-colectivas - 0/html/2d1a 7a6c-5628-4820-b85a-6383373e1fee_7. html\#I_0_>.

Navidad y Corpus Christi, festejados por los mejores ingenios de España en diez y seis autos a lo divino, diez y seis loas, y diez y seis entremeses: representados en esta corte y nunca hasta ahora impresos (1664): Madrid, por Joseph Fernández de Buendía, a costa de Isidro de Robles.

Pedraza Jiménez, Felipe B. (ed.) (1993): Lope de Vega, Rimas (tomo I), Madrid, Servicio de Publicaciones de la Universidad de Castilla la Mancha.

Pérez de Montalbán, Juan (1632): Para todos, ejemplos morales, humanos y divinos en que se tratan diversas ciencias, materias y facultades: repartidos en los siete días de la semana, Madrid, en la Imprenta del Reino, a costa de Alonso Pérez [su padre].

Plata, Fernando (2006): "La polémica en torno a La Perinola de Quevedo con un texto inédito", La Perinola: Revista de investigación quevediana, X, pp. 245-256.

Rodríguez Morales, Carlos (2008): "El licenciado Diego Ramos del Castillo, de Tenerife a Madrid (1630-1690)", Cartas diferentes. Revista canaria de patrimonio documental, IV, pp. 261268.

Rodríguez Ortega, Davinia (2017): "Heredera de Pedro Madrigal: María de Quiñones, impresora de ingenios áureos", Estudos Ibero-Americanos, v. 42, n. 3, pp. 1066-1094.

Rojas Zorrilla, Francisco de (1655): Autos sacramentales: con cuatro comedias nuevas y sus loas y entremeses: primera parte, Madrid, por María de Quiñones, a costa de Juan de Valdés.

Ruano de la Haza, José María (2015): "La publicación de los autos de Calderón (1655-1717)", Bulletin of Spanish Studies, 92, 8-10, pp. 283-309.

Ruano de la Haza, José María (ed.) (1995): "Introducción”, en Pedro Calderón de la Barca, Andrómeda y Perseo, Pamplona/Kassel, Universidad de Navarra/Reichenberger, pp. 11-133.

Tirso de Molina (1635): Deleitar aprovechando, Madrid, en la Imprenta Real, a costa de Domingo González.

Urzáiz Tortajada, Héctor (2001): "Las técnicas de reescritura en el auto La orden de Melquisedech: ¿autoplagio o reelaboración?”, en Felipe B. Pedraza, Rafael González Cañal y Elena E. Marcello (eds.), Calderón: sistema dramático y técnicas escénicas, Cuenca, Ediciones de la Universidad Castilla-La Mancha, pp. 335-362.

Urzáiz Tortajada, Héctor (2002): Catálogo de autores teatrales del siglo XVII, Madrid, Fundación Universitaria Española.

Valdivieso, José de (1622): Doce autos sacramentales, y dos comedias divinas, Toledo, por Juan Ruiz, a costa de Martín Vázquez de la Cruz.

Vega García-Luengos, Germán (2003): "La transmisión del teatro en el siglo XVII", en Javier Huerta Calvo (coord.), Historia del teatro español, vol. 1, pp. 1289-1320.

Vega García-Luengos, Germán (2008): "Consideraciones sobre la configuración del legado de comedias de Calderón”, Criticón, CIII-CIV, pp. 249-271. 
Vega García-Luengos, Germán (2010): "El prodigio de los montes y mártir del cielo (Santa Bárbara)", en Pablo Jauralde Pou (dir.), Diccionario filológico de literatura española. Siglo XVII, vol. I, Madrid, Castalia, s. v.

Vega, Lope de (1604): El peregrino en su patria, Sevilla, por Clemente Hidalgo.

Fecha de recepción: 21 de abril de 2016

Fecha de aceptación: 23 de junio de 2016 